\title{
Hydrogeochemical modeling of the deep water composition in the Strengbach critical zone observatory
}

\author{
JULIEN ACKERER ${ }^{1}$, CORALIE RANCHOUX ${ }^{2}$, YANN \\ LUCAS $^{2}$, DANIEL VIVILLE ${ }^{3}$, ALAIN CLEMENT ${ }^{2}$, \\ BERTRAND FRITZ ${ }^{4}$, CATHERINE LEROUGE ${ }^{5}$, GERHARD \\ SCHAFER $^{2}$ AND FRANCOIS CHABAUX ${ }^{6}$ \\ ${ }^{1}$ ITES CNRS Unistra ENGEES UMR 7063 \\ ${ }^{2}$ université de strasbourg \\ ${ }^{3}$ ITES (CNRS/U. Strasbourg) \\ ${ }^{4}$ LHYGES (UDS-CNRS) \\ ${ }^{5} \mathrm{BRGM}$ \\ ${ }^{6}$ ITES CNRS UMR 7063 Université de Strasbourg ENGEES \\ Presenting Author: julien.ackerer@orange.fr
}

Little is known about the deep water circulation and the role of deep weathering processes on the Critical Zone (CZ) evolution. In this study, main fractures from four deep boreholes $(0-120 \mathrm{~m})$ and water collected from fractures were analyzed to improve our understanding of the deep $\mathrm{CZ}$ in a granitic headwater watershed (Strengbach watershed, France). Geochemical analysis indicates that chemical composition of deep water is clearly different than subsurface waters, with higher mean concentrations and stronger spatial variability across the watershed. Hydrogeochemical modeling results highlight the difference of functioning between subsurface system (springs, piezometers, and stream waters) and deep system (deep water from borehole fractures). The subsurface system is characterized by fairly homogeneous water flow, high mean pore velocities, and water-rock interactions in a porous regolith, while the deep water circulation behaves much more as independent systems along fractures, with low mean pore velocities, and variable mineralogy and hydrodynamic conditions. A state of chemical equilibrium can also be reached along fractures in the deep $\mathrm{CZ}$ for some primary minerals (biotite and K-feldspar), a feature never observed so far in the simulations of subsurface water chemical composition. Even if the deep water exhibits higher solute concentrations, significantly lower mean pore velocities inferred in the fractured zones imply that the deep water is responsible for a negligible part of the total hydrologic and weathering fluxes in the watershed $(<1 \%)$. The limited role of the deep weathering processes compared to the subsurface processes suggests an up to bottom control of the $\mathrm{CZ}$ evolution at a millennial timescale. Our results also indicate that the majority of fresh water available for water supply at a human timescale originates from subsurface waters, as the deep water circulation is too low for being critical at a timescale relevant for societal needs in this type of geological context. 